\title{
Beyond Linguistic Purism in Language-in-Education Policy and Practice: Exploring Bilingual Pedagogies in a Hong Kong Science Classroom
}

Lin, A. M. Y. (2006). Beyond linguistic purism in language-in-education policy and practice: Exploring bilingual pedagogies in a Hong Kong science classroom. Language and Education, 20(4), 287-305.

\begin{abstract}
This paper proposes to overcome the traditional essentialist and dichotomous ways of conceptualizing language and language pedagogies, i.e., to go beyond linguistic purist perspectives. Analyzing bilingual teaching practices in a science lesson, this paper proposes that practical bilingual pedagogies can be developed to help students in bilingual education programmes to access dominant linguistic resources and discourses by capitalizing on their indigenous linguistic and cultural resources.
\end{abstract}

\section{Introduction}

Language-in-education (LIE) policy debates in postcolonial contexts have all too often been stultified by dichotomous oppositions: English or mother tongue? Individual rights or group rights? Socioeconomic mobility or cultural rootedness? Modernization or preservation? Globalization or localization? Is it possible to imagine ways out of these dichotomies? Is it possible to imagine ways in which a student speaking a home language other than Global English and the national/regional standard languages can learn Global English, the national/regional standard languages and the socioeconomically important discourses of science and technology without neglecting proficiency in their indigenous languages? How can we imagine and develop ways in which a state or government can provide educational facilities to democratize the acquisition of socioeconomically dominant discourses while at the same time without neglecting protective group rights for indigenous communities and their languages (Canagarajah, 2005)?

This paper proposes that to resolve tensions generated by these dichotomies, we have to overcome the traditional essentialist and dichotomous ways of conceptualizing language and language pedagogies, i.e., to go beyond linguistic purist perspectives. Analyzing the bilingual pedagogical practices in a Hong Kong science classroom, the paper proposes that practical bilingual pedagogies can be developed to help students access dominant discourses by capitalizing on their indigenous linguistic and cultural resources.

\section{Beyond Linguistic Purism: Emergence of Hybridized Multilingual/Multicultural Identities and Discursive Practices in Asian Societies}

Is English an imposed language, a vehicle of linguistic and cultural imperialism via the new wings of science and technology and global capitalism, and a killer language that threatens the continued existence (e.g., learning and use) of other regional and national languages and cultures in ex-colonies (e.g., Phillipson, 1997)? Or is it merely a medium for international communication that exists side by side with other local languages which different peoples keep for expressing their local identities (e.g. Crystal, 1997)? It seems that both positions seem to be a simplification of what usually is a much more complex 
situation. Instead of trying to argue for essentialized positions in the abstract, perhaps we should go beyond such a totalizing, dichotomous way of thinking and actually look at each specific sociocultural context in all its concrete complexities.

For instance, in a study (Lai, 2003) of young people's cultural identification patterns and language attitudes, it was found that young people who identify themselves as Hong Kongers are also affectively inclined towards both Cantonese and English. To them, Cantonese and English are not mutually exclusive and they find it natural (or almost impossible not) to mix English words into their everyday Cantonese (see Li and Tse, 2002). Also, given the special sociopolitical, historical context of Hong Kong, it seems that many Hong Kong people did not entirely accept British colonial rule in the pre-1997 era and yet are equally ambivalent about Socialist Chinese domination in the post-1997 era. Such mixed, ambivalent feelings in national and sociocultural identification seem to correlate with the freely intertwining of Cantonese and English words in the everyday public and private life of Hong Kong people, and these "non-pure" linguistic practices seem to be playing an important role in marking out the hybridized, multilingual Hong Kong identity - they seem to serve as distinctive linguistic and cultural markers of "Hong Kong-ness". It is almost like saying: We're Hong Kong-ese and I don't care whether I'm speaking "pure Chinese/pure English” or not!

In this sense then if the hybridized Hokkien-sounding variety of English--"Singlish"--is a linguistic marker of the distinctive hybridized Singaporean identity (Chua, 2003), then the so-called "mixed code" of Hong Kong seems to be its counterpart in Hong Kong. Like Singlish, the so-called "Hong Kong mixed code" is not a monolithic, fixed entity. In practice, it consists of a whole continuum of different styles of speaking and writing, from the use of here and there a few English lexical items in otherwise Cantonese utterances/sentences to the intertwining of extended English and Cantonese utterances/sentences (Lin, 2000). From the perspectives of performativity theory on languages and communication resources (Pennycook, 2004), it will be a better idea not to view languages as 'pure', separate stable systems with solid, fixed boundaries. As Pennycook (ibid) argues, the idea of languages as discrete, fixed, monolithic entities with solid boundaries is actually the product of colonial knowledge production. In practice, people draw on a whole range of linguistic resources which cannot be easily classified as "separate languages" in their everyday discursive practices. As both Hornberger (2003, 2004) and Brutt-Griffler and Varghese (2004) pointed out, the categories of bilingualism are not fixed and immutable and the notion of a linguistically pure mother tongue is a political ascription. Parallel to people's hybridized discursive practices are their similarly hybridized sociocultural identities. For instance, among many Hong Kong people today, there do not seem to be any clear-cut "pure" sociocultural and linguistic identities such as those imposed by normative Chinese nationalism or Chinese culturalism-the Hong Kong people's sociopolitical and sociocultural identity seems to be always a "hyphenated" and hybridized one, indicating its "in-between-ness" (Abbas, 1997) and cannot be pigeonholed as only 'Chinese'.

Recent research has actually found that in East Asian cosmopolitan cities, there are increasing trans-national popular cultural flows and linguistic hybridization taking place. 
For instance, Rip Slyme, a popular rap group in Japan, has used English in their lyrics to fashion a kind of "double" identity (Pennycook, 2003):

... Rip Slyme locate their Japaneseness explicitly, yet at the same time they use the English word for Japanese, seeming in the same instant to refashion their identity from the outside. This Japanese identity is then both 'freaky' and 'double', the latter a recently coined term to describe people of mixed origin (Pennycook, 2003, p. 527).

What the theory of linguistic imperialism fails to show is perhaps how English can be actively taken up, how people can actually appropriate (i.e., claim ownership of) English and why people sometimes strategically choose to use English or code-switching (Lin, Wang, Akamatsu and Riazi, 2002). Pennycook (2003) observes that the linguistic imperialism theory cannot account for a sense of agency, resistance, or appropriation on the part of ex-colonized peoples. It tends to construct ex-colonized peoples as passive victims ( $\mathrm{Li}, 2002)$. Somehow between the dichotomous positions of uncritically celebrating the global spread of English as an innocuous tool for communication, science and technology (Crystal, 1997), and constructing English as a monolithic universal killer language colonizing relentlessly the local linguistic and cultural habitats of ex-colonial societies, we have to steer a level-headed, middle way by taking a socio-historically situated perspective; i.e., we need to look at each sociocultural context in all its complexities before jumping to a conclusion. Going beyond the debate between the 'imperialism-resistance' theories (e.g., Phillipson, 1992) and the 'postcolonial performativity' theories (e.g., Pennycook, 2003, 2004), we have to find a way of understanding and exposing new forms of inequalities in education and society and new productions of subaltern subjectivities (i.e., marginalized identities and an underclass sense of self; see Ashcroft, Griffiths and Tiffin, 1998) under forces of globalization. While doing critical education analysis we must also be wary of falling into the trap of doing merely essentialist identity politics (e.g., arguing that one's L1 must be more important than one's L2, or forcing school children and parents to choose between either L1 or L2 medium-of-instruction programmes; see Hornberger (2003, 2004)'s critique of educational and linguistic binaries). Rather, we must struggle to study the new material and institutional conditions that might lead to social and educational inequalities, and to explore practical alternatives to linguistic purist pedagogical models in language-ineducation (LIE) policy and practice to democratize the acquisition of socioeconomically important linguistic resources while at the same time capitalizing on indigenous linguistic and cultural resources (Lin and Martin, 2005).

New Intellectual Breakthroughs in LIE Policy and Practice in Postcolonial Contexts Cummins (1999) points out the need for breaking away from the either-or simple prescription (i.e., simply prescribing that no L1 is allowed or simply saying that L1 can be used without giving clear, systematic, guidelines). He calls for a more considered and systematic approach to L1 use:

[In the successful example of International High School in New York City], the [language] planning process involved changing the curriculum and assessment procedures to enable students to use their prior knowledge (much of it in their L1) 
to facilitate their learning and demonstrate what they had learned. Use of students' L1 was encouraged, as was a cooperative and supportive inquiry process. (Cummins, 1999, p. 13)

Canagarajah (2005) offers us insightful theoretical and practical directions alternative to traditional linguistic purist models in LIE policy, pedagogy and curriculum. He refers to how multiple languages 'jostle together in many domains of communication, functioning in a complementary, integrated, and fluid manner' (Canagarajah, ibid). Thus, we see that the postcolonial state's top-down language planning models have often unwittingly followed in the steps of their colonial masters: treating languages as discrete entities with fixed boundaries that can be neatly classified and manipulated in their policy models. As an alternative to these traditional, linguistic purist, colonialist LIE models, Canagarajah draws on Hornberger's (2003) model of continua of biliteracy as a useful alternative policy orientation to literacy:

Her continua of biliteracy model features dichotomous communicative constructs like oral/literate, vernacular/literary, micro/macro, and contextualised/decontextualised as a continuum, with the latter representing the traditionally more powerful and the former the traditionally less powerful values. Hornberger demonstrates how this model can be used in research and policymaking as a heuristic to understand the ways these features are (or can be) negotiated by a community to define its needs and aspirations. It is important to note that the choice between vernacular or lingua franca, oral texts or written texts, and narrative or academic discourse is not mutually exclusive. Each community will have to develop the mix of languages, literacies, and discourses that best suit its interests. This will be based on the history of that community, and the relationship between the languages in its environment. (Canagarajah, ibid)

Luke (2005) also proposes 'edgy hybrid blends of policy and practice, curriculum and pedagogy'. Canagarajah (ibid) urges us to conduct careful ethnographic research into the nitty-gritty of the everyday realities of students and teachers to come up with constructive suggestions for policy and practice alternatives to traditional linguistic purist models. Exploring the potential of bilingual pedagogical strategies must then be seen as a pedagogical breakthrough in the research on how to help rural or poor urban working class school children to acquire global, standard languages and literacies for wider communication and socioeconomic mobility while building on their indigenous linguistic resources.

\section{The Research Literature on Bilingual Pedagogical Strategies}

There exists a small but useful research literature on bilingual classroom practices and strategies (e.g., Martin-Jones and Heller, 1996; Heller and Martin-Jones, 2001; Lucas and Katz, 1994; Canagarajah, 1995; Lin, 1996, 2000; Martin, 2005). Usually, some kind of functional taxonomy is set up in these studies which illustrate how the use of bilingual classroom practices can achieve various useful linguistic, educational, affective and sociocultural functions. Tables 1 and 2 in the Appendix summarize some functional taxonomies found in the research literature. 
A cursory view of the functional taxonomies in Tables 1 and 2 shows us that the functions of bilingual classroom strategies seem to cluster on two major dimensions: (1) that of humanizing the classroom atmosphere and socialization of students into indigenous sociocultural values, and (2) building on students familiar lifeworld knowledge and linguistic resources to bridge the gap between the L2 school knowledge/discourses and the L1 home discourses.

While agreeing with the above-mentioned research studies and researchers on the need to breakthrough the monolingual principle, we also need to note that there is a diverse range of bi- and multi-lingual pedagogical practices in different classroom contexts. While some of these practices are effective with respect to their goals, some of them might be reproductive of the lack of linguistic capital on the part of both teachers and students (for example, Chick, 1996; for a critical analysis of Chick's study, see Lin and Luk, 2002). Also, if students English proficiency is very limited then English immersion education (i.e., teaching content in English) results in extensive text translation practices in the classroom, which seems to be educationally counterproductive and constitutes what Johnson called 'immersion under stress' (Johnson, 1997). The research question to be asked in our studies should, therefore, change from a simple yes-no question (i.e., should bilingual pedagogical strategies be used?) to a more nuanced set of wh-questions (i.e., when, how, in what classes, with whom, for what educational goals, ..., should bilingual pedagogical strategies be used?).

\section{Dilemmas Facing LIE Policy Makers in Postcolonial Asian Contexts}

Exploring bilingual pedagogies for limited English (L2) proficiency students who (or whose parents) desire to have an English (L2) medium education especially in science and math subjects for its socioeconomic and instrumental value has now become an urgent policy and practice imperative especially in postcolonial Asian contexts ${ }^{1}$ where renewed forces of economic globalization have driven state governments to reverse their former mother tongue (or national language) education policy to English medium education policy especially for science and math subjects. For instance, the Malaysian government, after over thirty years of using their national language (Bahasa Malaysia) as the medium of instruction at all levels of their education system after independence from Britain, re-instated English as the medium of instruction for science and math subjects starting from Primary 1, Form 1 and Form 4 (i.e., Grade 1, 7, and 10) in all public schools in September 2003 (see paper on Malaysia in this special issue). The Hong Kong postcolonial government, after re-instating the 'mother-tongue education' policy in over $70 \%$ of public secondary schools amidst strong protests from parents and school principals in September 1998 (see Poon, 2000 for an ethnographic description), is now also at a language-in-education policy crossroads faced with the societal demand for relaxing the mother-tongue education restriction to allow schools to re-instate some

\footnotetext{
${ }^{1}$ It has to be pointed out that these societies due to their former British colonial histories seem to be particularly obsessed with the importance of English in education (e.g., as medium of instruction in schools) when compared to other Asian contexts where the hegemony of English in education seems to be less prominent (e.g., in Japan, Korea or Taiwan).
} 
English medium classes especially for science and math subjects at Form 4 (Grade 10) with a view to preparing students for entry to universities (which are still largely English medium, especially for the professional, science and technological subjects). However, the policy makers are confronted with a difficult dilemma: as many students (and very often also teachers) in Hong Kong are not proficient in English enough to function competently in a purely English medium content lesson, will it be educationally responsible to allow schools to re-instate English medium in their science and math lessons if their students (or sometimes even teachers) are still struggling with English?

It is in this context of policy dilemmas that the following section on the analysis of a bilingual pedagogy in a science lesson has to be read. It will be shown in the analysis how a science teacher uses a systematic bilingual teaching approach to help students to understand the abstract scientific principles and theories by connecting these theories to students' familiar L1 lifeworld experiences while at the same time providing students with access to the English science discourse in their English science coursebook.

\section{Exploring a Viable Bilingual Pedagogy in a Science Lesson}

The science lesson data analysed in this section has come from a larger corpus of lesson data that the author has inherited from R. K. Johnson, former Professor of Education at the University of Hong Kong. R. K. Johnson was the first researcher in Hong Kong who started a series of studies in the 1980s (Johnson, 1983, 1985) on bilingual classroom strategies in English medium content lessons in secondary schools. Upon his retirement, Johnson passed his corpus of transcribed lesson data to the author ${ }^{2}$.

This historical corpus of bilingual lesson data is especially valuable for research on the possibility of developing viable bilingual pedagogies given the historical context of Hong Kong where after implementation of the government's linguistic streaming policy in 1998 and its explicit policy of banning bilingual classroom practices in the 1990s few researchers can have access to bilingual classrooms. Many teachers or school principals are reluctant to admit that they code-mix or code-switch in their EMI (English medium) classrooms even if in reality they find it necessarily to do so (for a historical background of medium-of-instruction policy debates in Hong Kong, see Lin, 1996, 1997, and Hopkins, this special issue).

Johnson $(1983,1985)$ fully transcribed five audio-taped junior secondary content lessons (Geography, History, Math, Science, Social Studies) from five different Anglo-Chinese secondary schools ${ }^{3}$. These lessons were described as successful lessons by Johnson as these teachers volunteered to join the study and they were identified as confident and competent teachers in the schools. The methodology used by Johnson cannot be said to

\footnotetext{
${ }^{2}$ The author is indebted to Johnson for his trusting her with this corpus of data for further analysis.

${ }^{3}$ Before the linguistic streaming policy implemented in September 1998 in Hong Kong, the majority of secondary schools in Hong Kong called themselves "Anglo-Chinese secondary schools" meaning that they officially used English as the medium of instruction for all content subjects; however, in reality, in many schools, while the written medium was English, the oral medium in the classroom was often bilingual.
} 
be ethnographic as teacher and student interview data did not seem to be included. We can say that Johnson mainly did a classroom transcript analysis. Also, due to the limitation of the data collection method (i.e., by putting an audio tape recorder on the teacher's desk), students' utterances were not recorded and the classroom transcripts do not show students' responses.

Although with these methodological limitations, Johnson focused on analysing the teacher's switched utterances in their discourse contexts. He identified four main factors associated with code-choice. English (the students' and teachers' L2) was found to be associated with text-dependent, formal, didactic and memory-based functions; whereas Cantonese (the students' and teachers' L1) was found to be associated with textindependent, informal, explanatory and understanding-based functions. For instance, when the teacher needs to explain the concepts in the text by drawing on or eliciting students' everyday life experience, the teacher will switch to Cantonese and ask questions related to students' experience in Cantonese (in a more 'informal, explanatory' mode). However, when the teacher wants to draw students' attention to the important technical terms or concepts in the textbook, the teacher will speak in English and will usually lecture (in a more 'formal, didactic' teaching style) in English, usually by reading out the English text on these important terms. In the classroom example analysed in the following paragraphs similar observations can be made (Table 3 in the Appendix summarizes Johnson's findings).

In this section a science lesson from Johnson's data corpus will be re-analysed in further detail to explore and illustrate the possibility of developing a viable bilingual pedagogical approach to provide limited English (L2) proficiency students with access to the science discourse while drawing on their L1 resources. The lesson focuses on teaching the students the scientific concepts related to the law of 'Brownian Motion', 'Kinetic Theory' and the title of the section being referred to in the students' science coursebook is: 'Evidence for particles'.

\section{A Procedural Description of the Lesson Structure:}

The lesson can be divided into two stages. In the first stage, the teacher sets up an experiment and groups of students take turn to come out to see him conduct the experiment. In the second stage of the lesson, the teacher discusses the phenomenon observed in the experiment and leads the class by a series of questions to an understanding of the scientific concepts related to 'Brownian motion' and 'Kinetic theory'. The following procedural description (Heap, 1985) of each stage will give the reader an overall sense of the structure of the lesson:

Stage (1): the Experiment Stage consists of the following teaching procedure:

1. The teacher asks 2 groups of students to come out to see him conduct an experiment.

2. The teacher sprinkles some powder onto a water basin filled with water, describing his action verbally and clearly to the students as he does it. 
3. The teacher asks the students to observe that the powder is floating on the surface of the water.

4. The teacher drops one tiny drop of oil onto the centre of the powder, describing his action verbally and clearly to the students as he does it.

5. The teacher asks the students to observe what happens to the powder, especially asking them to observe how the powder moves.

6. The teacher describes the manner of the movement of the powder to the students verbally several times, urging them to observe the powder's movement pattern.

7. The teacher asks students to go back to their seats and to think about why the powder moves the way it does after he has dropped a tiny drop of oil in the middle of it.

The teacher repeats Stage (1) until all groups of students in the class have come out to see him conduct the experiment.

Stage (2): the Discussion Stage consists of the following teaching procedure:

The teacher uses the IRF (Initiation-Response-Feedback) discourse format (Sinclair and Coulthard, 1975; Mehan, 1979; Heap, 1985; Lin, 1996, 1999) to ask a series of questions about what happened during the experiment and why it happened the way it did to lead the class towards arriving at a corpus of scientific explanations and definitions around the interrelated scientific concepts of 'Brownian motion', 'Kinetic theory' and the concepts that 'matter is made up of particles' and that 'particles are in continuous motion'. As the audiotape did not pick up students' responses, only teacher initiations and feedback are available for analysis. However, based on the available teacher talk we can still analyse how the teacher moves the lesson forward and leads students towards an understanding of the scientific concepts.

After gaining an overall sense of the structure of the lesson through the above synoptic procedural description, let us now focus on analyzing the teacher's bilingual teaching approach. The teacher uses Cantonese (L1) to do most of the teaching except when presenting a key L2 term or principle or when the discussion reaches its conclusion where the key scientific concepts, theories and principles are recapped in English (L2). This teaching pattern is highly systematic. Let us analyse excerpts from Stage 2 of the lesson to illustrate how the teacher conducts the post-experiment class discussion on the phenomena observed in the experiment in Stage 1 of the lesson. We shall in particular notice how the teacher achieves the following main pedagogical functions:

(1) Embedding the presentation of key L2 terms and concepts in a rich L1 semantic context

(2) Socializing students into the Observe-Wonder-Explain practice and attitude of scientific inquiry characteristic of scientists (Armstrong \& Chen, 2002)

(3) Illustrating abstract scientific concepts with concrete L1 everyday life experiences and example 


\section{(4) Summarizing what is taught in L2: Spelling out the core L2 scientific terms / drawing students' attention to the L2 science discourse in the L2 science coursebook and worksheets}

The lesson excerpt below is taken from the beginning of the Stage 2 when the teacher starts the class discussion on what was observed in the experiment:

Excerpt 1: (Cantonese utterances are transcribed in the Yale system and English glosses are put in pointed brackets immediately after the Cantonese utterances; English words used by the teacher are underlined for easy reference; the numbers show the sequence of consecutive speaking turns)

1. Tai-saai la, hah, <Saw everything already, right,>

2. Nah gam yih-ga nam-hah go yuhn-yan dim-gaai wuih haih gam ge lo wo. $<$ Now then, now think of the reason why this was so.>

3. Nah sau-sin ne daaih-gaa wuih mihng-baahk-dou di fan ne, powder aah, <Now first, all of us will understand the powder, powder that is,>

4. haih hou sai nap ge, haih-mh-haih aah? <are very small grains, right?>

5. Muih yat-nap, mui yat-nap, hou sai nap jeuih-maaih yat-deui ge. $<$ Each grain, each grain, very small grains gathering together.>

In Excerpt 1 above, we notice that the teacher first seeks confirmation (Line 1) with the class that they have already observed everything that happened in the experiment conducted earlier. The teacher then asks the students to "think of the reason why this was so" (Line 2). The teacher's utterance in Line 2 has the communicative function of announcing to the class what they are going to do in the rest of the lesson: to think of the reason why things happened the way they did in the earlier experiment. However, right after this announcement the teacher says they first will understand that the powder is very small grains gathering together (Lines 3-5). The only English word mixed into an otherwise all Cantonese sentence is "powder". This is the first key L2 term introduced by the teacher. It is important to note that the L1 discourse context surrounding the L2 word offers rich semantic annotation to the L2 word (In Line 3: "di fan ne" meaning "the powder" immediately precedes the first presentation of the L2 word "powder"). The L2 word "powder" is thus expected to cause little comprehension problems to the students. In the above few lines, the teacher seems to have succeeded in: (a) providing a rich L1 semantic context to embed the presentation of a key L2 term "powder", and (b) presenting in L1 the characteristic properties of "powder": very small grains gathering together. In the next excerpt which continues with Excerpt 1, we shall see how the teacher continues to socialize students into the systematic Observe-Wonder-Explain triadic sequence of actions characteristic of the scientific inquiry practice and attitude of the world's community of scientists. To make it easier to read the excerpt the original Cantonese utterances have been omitted from the transcript and only their English translations are shown and they are put in pointed brackets. English utterances or words mixed into the Cantonese utterances are underlined and bolded. 


\section{Excerpt 2:}

6. <Then when we put the powder into the water at that time,>

7. <you already saw it was like what?>

8. < Slowly spreading out, $>$

9. <slowly spreading->

10. $<$ But when I again dropped a drop of oil in its centre, $>$

11. <you then saw how it was?>

12. $<$ Those powder spread out very quickly, $>$

13. <and was in what kind of shape did it spread out?>

14. <Like what?>

15. <Like what, at that time the situation was like what?>

16. $<$ I think when we pass by rivers $>$

17. <you also would do this.>

18. <Yes, (it's) like the situation when you throw a small pebble into the water>

19. $<$ There would arise something, $>$

20. <called what?>

21. <Ripples, right? O.K.>

22. $<$ Is there any student who has played this?>

23. <that is, have thrown pebbles into the water and seen this situation.>

24. <If you have never tried this before, someday when you have the opportunity to go to the riversides, $>$

25. <or the seaside, try throwing a pebble onto that calm water-surface.>

26. $<$ Then you will see, it scatters, $>$

$27 .<$ all the way, layer by layer $>$.

28. $<$ Then this can prove one thing.>

$29 .<$ I only dropped one drop of oil into it. $>$

$30 .<$ That drop of oil certainly was what?>

31 made up of a lot of small particles.

32. <Only one drop.>

33. <Then, but, when I (as soon as I) have dropped into it ->

34. $<$ when I dropped this drop of oil onto the water-surface, $>$

35. <those particle then what?>

36. $<$ Spread out. $>$

37. $<$ Then as they spread out, $>$

38. <scattered outward,>

39. <and what does it do to the powder originally on the water surface?>

40. $<$ Pushed outward. $>$

41. $<$ Now we sprinkle some powder, $>$

42. <the aim of which is to let you see the water spread out like this, >

43. <that is to see the oil particle spread out.>

44. $<$ If there is no powder there, $>$

45. <and we, just like this, drop a drop of oil into (the water),

46. <you would not be able to see the oil spread out.>

47. < Then sometimes we would do so: >

48. < There is a glass of water, we drop a drop of ink into it, > 
49. <you would see the drop of ink, now (is it)?>

50. < Slowly and gradually spread out.>

51. <Then these (things) are to prove that particles are made up, eh,>

52. matters are made up of small particles a.

53. Question A, you answer, what happens? The oil particles spread out laak. S-P-R-E-A-D. Explain why this happens.

In the above excerpt, we see how the teacher systematically guides the students through the observation of what happened when he dropped a drop of oil in the middle of the powder on the water surface. He then uses the daily life example of throwing a pebble into the calm water causing layers and layers of ripples to spread out to illustrate the experimental situation when a drop of oil was dropped into the middle of the powder on the water surface (Lines 16-27). He then presents the concept that the drop of oil is "made up of a lot of small particles" (Line 31). We notice that all along he has been speaking in Cantonese until he presents the key scientific concept and he presents this key concept in L2. The rich L1 semantic context embedding (i.e., both preceding and following) this L2 presentation is likely to make the comprehension of this key L2 concept (mediated in the L2 science discourse: "made up of a lot of small particles") possible for the students. The same concept is re-presented in more scientific detail in Line 52: "matters are made up of small particles". We notice how the teacher gradually and systematically introduces the L2 scientific concepts: first to present to students the specific concept that a drop of oil is "made up of a lot of small particles" (Line 31), then to present to students the more general scientific concept that "matters are made up of small particles" (Line 52). In between Lines 31 and 52 the teacher offers a rich L1 semantic context including another example of dropping a drop of ink into a glass of water to illustrate the phenomenon of the spreading out movement of particles. We can also see that all the L1 discussion and examples lead towards and culminate in the presentation of the L2 experiment worksheet which poses the questions of what happens when a drop of oil is dropped into the middle of the powder on the water surface and which asks students to explain why this happens (Line 53). All the foregoing L1 discussion, questions, examples and explanations can thus be seen as a preparation of the students to answer these scientific questions written in L2 (English) on the experiment worksheet. With the rich semantic context offered by the teacher the students should now be ready to tackle the $\mathrm{L} 2$ science discourse in the science curriculum texts. We notice that the teacher actually provides the students with the L2 science discourse, "The oil particles spread out", to answer the question in the L2 science text; he also spells out the key L2 word ("spread") for the students (Line 53) with a view to facilitating the students' actual writing down of the L2 scientific answer to the L2 scientific question on the text.

A critic may say that the teacher in providing the L2 answer to the L2 question on the text might have short-circuited students' own inquiry process and encouraged students to just dictate the L2 answer from the teacher to the text. However, if we look at the lesson as a whole, we see how the teacher uses the IRF discourse format to engage the students in a Socratic type of dialogue to guide the students step by step towards understanding the key scientific concept that a drop of oil and then matter is made up of a lot of small particles. 
The provision of the L2 science discourse (in Line 53) for the students to tackle the L2 science question in the text can be seen as a way of giving students access to the L2 science discourse while embedding and annotating this L2 science discourse in a rich L1 semantic context full of familiar L1 lifeworld examples (pebble thrown into the water causing ripples; a drop of ink dropped into in a glass of water and spreading out in the water) and explanations. Later on in the lesson transcript we see how the teacher tells (in L1) the scientific inquiry stories of Brown, Watt and Fleming in illustrating how these great scientists made important scientific discoveries (discovering the principle of "Brownian motion", inventing the steam engine, and discovering penicillin) by first paying attention to small details in naturally occurring everyday phenomena and then by wondering why and then by finding explanations which led to their discoveries. When the students' L2 proficiency is limited, using L1 to relate to students these scientific inquiry stories of great scientists in the world can serve an important function of socializing students into the inquiry practice and attitude of the community of scientists. It serves the function of socializing students into the identity and practice of scientists. If the teacher is limited to using L2 only in the science lesson, this important function cannot be easily achieved when the students' L2 proficiency is limited.

In Excerpt 3 below, we shall see how the teacher summarizes what is taught in L2: spelling out the core L2 scientific terms and drawing students' attention to the L2 science discourse in the coursebook.

\section{Excerpt 3:}

218. <Now, then we see the oil particles spread out. $>$

219. <Then, and, >

220. <hopefully next lesson we can see these smoke particles, $>$

221. < (are) moving.>

222. $<$ Now, then, all these situations, $>$

223. <together, we call it the kinetic theory, kinetic theory.>

224. <Then this theory says, that is, all matter is>

225. made up of small particles, and the small particles are always moving.

226. They are in continuous motion.

227. < (That is) we call it a theory, a law, $>$

228. <a logic, that is, called theory, kinetic theory. >

229. < "Kinetic" this word we all know. Kinetic theory.>

230. <Only two sentences:>

231. Part - matters are made up of small particles. The particles are always moving.

232. <Then this is kinetic theory.>

233. <Then in the next lesson we, following this, will study>

234. <these particle(s), in solid,>

235. <in liquid and in gas, are there any differences?>

236. <Now, we all know that,>

237. <all things are made up of small particles, >

238. <then, but, why the world's things will have three kinds of states?> 


\section{Solid, liquid and gas.}

$240 .<$ Then, this is of course concerned with the relations among the particles.

241. $<$ So, therefore, in the next lesson we will see these particles, $>$

242. <in solid, liquid and gas, is there any difference, okay.>

243. <Now this evening remember to take a look at page seventy-four,>

244. <this paragraph (of the book).>

In the above excerpt, we see how the teacher explains, annotates and illustrates some core scientific concepts and theories ("Kinetic Theory", "matter is made up of small particles and the small particles are in continuous motion"; see Lines 223-231) by embedding these core elements of the L2 science discourse in an elaborate L1 semantic context of explanations and examples. The key terms for the three states of matter--'solid, liquid and gas'--are also introduced in English amidst an otherwise largely Cantonese discourse (Lines 235, 239, 242). The teacher's explanation of the key concepts and key terms culminates in the concluding part of the lesson when the teacher draws students' attention to the relevant section of the science text in the book and asks students to go home and read that specific paragraph (Lines 243-245). The whole lesson can be said to prepare students to tackle and understand the specific L2 science discourse on this topic in the book.

\section{Providing limited-English-proficiency students with access to the English science discourses via bilingual pedagogies}

The above lesson transcript analysis aims at showing how a bilingual science teacher uses a bilingual teaching approach to provide limited-English-proficiency students with access to the English science discourse. While critics may say that students will be deprived of the much-needed L2 exposure to learn how to give explanations, arguments and examples in $\mathrm{L} 2$, we have to acknowledge that what the teacher is doing is basically helping students to understand the L2 science discourse in the L2 curriculum (and texts) and to be able to respond with appropriate L2 science discourse to questions in the L2 science curriculum. Lemke in his book on science classrooms (1990) concludes that learning science basically involves the learning or acquiring of a set of science discourses and their relations. Mastering science is thus mastering the discourses of scientific concepts and theories and the interrelationships among them. When the bilingual teacher provides a rich L1 semantic context (of L1 lifeworld examples and experiences familiar to the students) to embed the presentation of the lexico-grammatical elements of the L2 science discourse to facilitate students' understanding of L2 science discourses (i.e., the concepts and theories mediated in specific L2 science lexico-grammatical expressions such as "matter is made up of small particles", "particles are in continuous motion", "this is called Kinetic Theory"). We have to notice that the mastering of the science discourses (or the science genres) is not automatic and involves a lot of concrete illustration of these abstract general concepts with familiar daily life examples, and the corresponding shuttling to and fro between the L2 science discourses and the familiar L1 lifeworld discourses (Luke, Freebody, Cazden and Lin, 2005). Given this situation, it is difficult for limited-English-proficiency students to access (e.g., understand and acquire) the 
English science discourse without the linguistic and cultural bridging functions offered by the L1 semantic context that the bilingual teacher provides.

While the students might not have exposure to English for giving lively explanations and examples, the students are at least helped to access and acquire the English science discourse through the help of the bilingual teaching approach. When language-ineducation policy makers consider their options, it has to be made clear that with the majority of limited-English-proficiency students in EFL (English as foreign language) contexts in many Asian societies, realistic educational goals have to be set up. If the purpose of teaching science and math school subjects in English (e.g., the recent policy implemented in Malaysia) is mainly that of enabling students to be able to access the global English discourses of science and technology, then it is not realistic to also expect students emerging from these science and math lessons to speak fluent everyday English. A more realistic educational goal is to facilitate language socialization of students into the English science discourses and genres. It is more realistic to aim at helping students to be able to understand English science texts and to be able to express core science concepts and theories in the appropriate science language (and genre). Much of the frustration of policy makers might have resulted from setting unrealistic L2 language goals for bilingual education programmes. If students learn science and math in L2, it is not reasonable to expect them to be fluent in everyday social English, for instance. Other kinds of educational programmes (e.g., a conversational English language programme using a communicative language teaching approach perhaps) might be more effective than immersing students in English science and math classes for achieving that kind of social interactional competencies in English.

\section{Limitations of this Study and Proposed Directions for Future Research}

Due to the limited ways in which Johnson' classroom data was collected (e.g., little student output was recorded as the tape recorder was placed on the teacher's desk; little ethnographic background information and no interview information on the teacher and students), the lesson transcript analysis conducted above cannot show whether students actually show understanding of the concepts being explained in Cantonese, nor any productive output from students can be seen in the transcript. However, Johnson did mention in his report (1985) that the teachers were identified as good teachers in the school. In Hong Kong school culture, for teachers to be identified as good teachers by the school authorities, the results of their students have to be good. This then can perhaps provide some indirect evidence that the students seemed to be doing well in their assignments, tests and exams, which were all in the medium of English in an EMI school.

It is, therefore, the argument of this paper that it is important to revisit the critique of the hitherto exclusion of serious research attention to bilingual pedagogies as viable practice alternatives. This exclusion is rationalized mainly through the invisible ideological function of linguistic purism embedded in the so-called "common sense" of many educators, the public and policy makers who often pre-reflectively rule out the possible educational functions that can be served by bilingual pedagogies. 
However, given the limited nature of the data from Johnson, the lesson analysis in this paper alone cannot provide solid evidence for the effectiveness of the kind of bilingual pedagogy practiced by the teacher shown in the data excerpts above. It is also important to note that the hegemony of English as the medium of science and academic learning was also reproduced in the lesson analysed above. Basically the bilingual teacher seemed to be using Cantonese to bridge the gap between the students' everyday lifeworld (largely mediated in Cantonese) and the school world where academic science is supposed to be taught in English (see similar curriculum bridging and academic content transmitting roles performed by bilingual teachers in Benson, 2004 and Creese, 2004). The teacher seemed to aim at enabling students to understand the science text in English and to answer science questions in English. The ultimate target seemed to be that with this bridging work by using Cantonese to draw on students' lifeworld experiences, students are helped to understand core scientific concepts and terms, which are, however, always mediated in English, not in Cantonese or Chinese. In this way the use of bilingual pedagogical strategies serves the purpose of establishing English academic monolingualism rather than Chinese-English academic bilingualism (i.e., students will not learn the Chinese or Cantonese counterparts of theEnglish scientific terms). This point was also elaborated and exemplified with classroom examples in Lin (1996). Alternative ways of doing this science lessons using bilingual pedagogical strategies need to be further explored.

It is the hope of the author that in the future more serious research attention will be given to the exploration and development of a range of different systematic, viable bilingual pedagogies for bilingual education programmes where students with limited English (L2) proficiencies are nevertheless faced with the task of learning the L2 academic or scientific discourses for various globalization (or national economic development) needs as witnessed in many Asian contexts today. However, to yield more conclusive evidence, in future research it is recommended that both interpretive discourse analytic approaches and (quasi-) experimental approaches (Johnson, 1992) should be employed to develop an appropriate bilingual pedagogy for a situated educational context. For instance, a discourse analytic study that examines the effectiveness of a specific bilingual teaching approach should also be complemented with a pre-test and post-test or control group research study of two similarly matched classrooms (e.g., with one class using a bilingual pedagogy and one class using a monolingual pedagogy) to measure students' gains in comprehension of the L2 science discourse and their productive competencies in performing tasks in the L2 science discourse. It is only with the development of a rigorous multi-disciplinary research paradigm that gives serious attention to researching the viability of various bilingual pedagogies for specific educational contexts that we will be able to make some constructive breakthroughs in the tired debate on what kinds of pedagogical practice can help solve some of our LIE policy dilemmas (e.g., how to help limited-English-proficiency students access the global English discourses of science and technology).

\section{Acknowledgements:}

The author wishes to thank the editor and three anonymous reviewers for their very useful comments on an earlier draft of this paper. Special thanks also go to R. K. 
Johnson for giving permission to the author to use his classroom transcript data for research purposes.

\section{References:}

Armstrong, S., \& Chen, M. (Eds.) (2002). Edutopia: Success stories for learning in the digital age. San Francisco, CA: Jossey-Bass.

Abbas, M. A. (1997). Hong Kong: Culture and the politics of disappearance. Minneapolis: University of Minnesota Press.

Ashcroft, B., Griffiths, G., and Tiffin, H. (1998). Key concepts in post-colonial studies. London: Routledge.

Benson, C. (2004).Do we expect too much of bilingual teachers? Bilingual teaching in developing countries. International Journal of Bilingual Education and Bilingualism, 7 (2-3), 204-221.

Brutt-Griffler, J., and Varghese, M. (2004). Introduction. International Journal of Bilingual Education and Bilingualism, 7 (2-3), 93-101.

Canagarajah, A. S. (1995). Functions of code switching in the ESL classroom: Socialising bilingualism in Jaffna. Journal of Multilingual and Multicultural Development, 16(3), 173-196.

Canagarajah, A. S. (2005). Accommodating tensions in language-in-education policies. In Angel Lin and Peter Martin (Eds.), Decolonization, Globalization: Language-ineducation policy and practice. Clevedon: Multilingual Matters.

Chick, J. K. (1996). Safe talk: Collusion in apartheid education. In Coleman, H. (Ed.), Society and the language classroom (pp. 21-39). Cambridge: Cambridge University Press.

Chua, B. H. (2003). Life is not complete without shopping: Consumption culture in Singapore. Singapore: Singapore University Press.

Creese, A. (2004).Bilingual teachers in mainstream secondary school classrooms: Using Turkish for curriculum learning. International Journal of Bilingual Education and Bilingualism, 7 (2-3), 189-203.

Crystal, D. (1997). English as a global language. Cambridge, U.K.: Cambridge University Press.

Cummins, J. (1999). Medium of instruction in schools: The case of Canada and the United States. Regional report submitted to SCOLAR, Hong Kong Government.

Heap, J. L. (1985). Discourse in the production of classroom knowledge: Reading lessons. Curriculum Inquiry, 15, 3, 345-279.

Heller, M., \& Martin-Jones, M., (Eds.) (2001). Voices of authority: Education and linguistic difference (pp. 139-168). West Port, Connecticut: Ablex.

Hornberger, N. (2003). Multilingual language policies and the continua of biliteracy: An ecological approach. In N. H. Hornberger (Ed.), Continua of biliteracy: An ecological framework for educational policy, research, and practice (pp.315-339). Clevedon: Multilingual Matters.

Hornberger, N. (2004). The continua of biliteracy and the bilingual educator: Educational linguistics in practice. International Journal of Bilingual Education and Bilingualism, 7 (2-3), 155-171. 
Johnson, D. M. (1992). Approaches to research in second language learning. New York, Longman.

Johnson, R. K. (1983). Bilingual switching strategies: a study of the modes of teachertalk in bilingual secondary school classrooms in Hong Kong. Language Learning and Communication, 2(3), pp. 267-285.

Johnson, R. K. (1985). Report of the ELTU study of the oral medium of instruction in Anglo-Chinese secondary school classroom. Hong Kong: Faculty of Education, University of Hong Kong.

Johnson, R. K. (1997). The Hong Kong education system: Late immersion under stress. In R. K. Johnson, \& M. Swain (Eds.), Immersion Education: International Perspectives, pp. 171-189. Cambridge: Cambridge University Press.

Lai, M.-L. (2003). Cultural identity and language attitudes in postcolonial Hong Kong. Paper presented at the International Conference in Language, Education and Diversity, November 26-29, 2003, University of Waikato, New Zealand.

Lemke, J. L. (1990). Talking science: Language, learning, and values. Norwood, New Jersey, Ablex Publishing Corporation.

Li, D. C. S. (2002). Hong Kong parents' preference for English-medium education: Passive victims of imperialism or active agents of pragmatism? In A. Kirkpatrick (Ed.), Englishes in Asia: Communication, identity, power and education (pp. 29-62). Melbourne: Language Australia.

Li, D. C.S., \& Tse, E. C.Y. (2002). One day in the life of a purist. International Journal of Bilingualism, 6(2): 147-202.

Lin, A. (1996). Bilingualism or linguistic segregation? Symbolic domination, resistance and code-switching in Hong Kong schools. Linguistics and Education, 8(1), pp. 49-84.

Lin, A. (1997). Bilingual education in Hong Kong. In J. Cummins, \& D. Corson (Eds.), Encyclopedia of language and education, Volume 5: Bilingual education (pp. 281289). Dordrecht, the Netherlands: Kluwer Academic Publishers.

Lin, A. (1999). Doing-English-lessons in the reproduction or transformation of social worlds? TESOL Quarterly, 33(3), 393-412.

Lin, A. (2000). Deconstructing "mixed code". In Li, D. C. S., Lin, A. M. Y., and Tsang, W. K. (Eds.), Language and education in post-colonial Hong Kong (pp. 179-194). Hong Kong: Linguistic Society of Hong Kong.

Lin, A., \& Luk, J. (2002). Beyond progressive liberalism and cultural relativism: Towards critical postmodernist and sociohistorically situated perspectives in ethnographic classroom studies. Canadian Modern Language Review, 59(1), 97-124.

Lin, A., \& Martin, P. (2005). From a critical deconstruction paradigm to a critical construction paradigm. In A. Lin \& P. Martin (Eds.), Decolonization, Globalization: Language-in-education policy and practice. Clevedon: Multilingual Matters.

Lin, A., Wang, W., Akamatsu, A., \& Riazi, M. (2002). Appropriating English, expanding identities, and re-visioning the field: From TESOL to Teaching English for Glocalized Communication (TEGCOM). Journal of Language, Identity and Education, 1(4), 295316.

Lucas, T., \& Katz, A. (1994). Reframing the debate: The roles of native languages in 
English-only programs for language minority students. TESOL Quarterly, 28 (4), 537562.

Luke, A. (2005). On the possibilities of a post-postcolonial language education . In Angel Lin and Peter Martin (Eds.), Decolonization, Globalization: Language-in-education policy and practice. Clevedon: Multilingual Matters.

Luke, A., Freebody, A., Cazden, C., \& Lin, A. (2005). Developing a research coding scheme for Singaporean classrooms. Paper presented in the AERA conference, April 2005, Montreal, Canada.

Martin, P. (2005). 'Safe' language practices in two rural schools in Malaysia: Tensions between policy and practice. In Angel Lin and Peter Martin (Eds.), Decolonization, Globalization: Language-in-education policy and practice. Clevedon: Multilingual Matters.

Martin-Jones, M. and Heller, M. (1996). Introduction to the special issues on education in multilingual settings: Discourse, identities and power. Linguistics and Education, 8(1): 3-16.

Mehan, H. (1979). Learning lessons: Social organization in the classroom. Cambridge, Mass.: Harvard University Press.

Pennycook, A. (2003). Global Englishes, Rip Slyme, and performativity. Journal of Sociolinguistics, 7(4), 513-533.

Pennycook, A. (2004). Performativity and language studies. Critical Inquiry in language studies, 1(1), 1-26.

Phillipson, R. (1992). Linguistic imperialism. Oxford: Oxford University Press.

Phillipson, R. (1997). Realities and myths of linguistic imperialism. Journal of Multilingual and Multicultural Development, 18(3), 238-248.

Poon, A. (2000). Medium of instruction in Hong Kong: Policy and practice. Lanham: University Press of America.

Sinclair, J., \& Coulthard, M. (1975). Towards an analysis of discourse. London: Oxford University Press. 


\section{Appendix: \\ Table 1: Some Functional Taxonomies in the Research Literature on Bilingual Classroom Strategies (exemplifying classroom excerpts are omitted)}

\begin{tabular}{|c|c|}
\hline $\begin{array}{l}\text { Use of students' native lang } \\
\text { Programmes (SAIP) for Li } \\
\text { from Lucas \& Katz, 1994): }\end{array}$ & $\begin{array}{l}\text { pecial Alternative Instructional } \\
\text { ity Students in the US (Summarized }\end{array}$ \\
\hline Students: & Teachers: \\
\hline To assist one another & To check comprehension \\
\hline To tutor other students & To translate a lesson \\
\hline To ask/answer questions & To explain an activity \\
\hline To use bilingual dictionaries & To provide instruction \\
\hline To write in native language & To interact socially \\
\hline To interact socially & \\
\hline $\begin{array}{l}\text { Use of Tamil-English Codes } \\
\text { (Summarized from Canaga }\end{array}$ & SL Classrooms in Jaffna, Sri Lanka \\
\hline Micro-Functions: Codeswitcl & ssroom: \\
\hline Classroom management: & Opening the class \\
\hline & Negotiating directions \\
\hline & Requesting help \\
\hline & Managing discipline \\
\hline & Teacher encouragement \\
\hline & Teacher compliments \\
\hline & Teacher's commands \\
\hline & Teacher admonitions \\
\hline & Mitigation \\
\hline & Pleading \\
\hline & Unofficial interactions \\
\hline Content transmission: & Review \\
\hline & Definition \\
\hline & Explanation \\
\hline & Negotiating cultural relevance \\
\hline & Parallel translation \\
\hline & Unofficial student collaboration \\
\hline Macro-Functions: Socioeduc & ations \\
\hline By mixing Tamil and English & are able to pretend that they are still using \\
\hline Tamil (for nationalist solidari & hile claiming the symbolic rewards \\
\hline $\begin{array}{l}\text { associated with English. The } \\
\text { and school, or cultural knowl }\end{array}$ & $\begin{array}{l}\text { f Tamil bridges the gulf between the home } \\
\text { emic knowledge. Classroom codeswitching }\end{array}$ \\
\hline $\begin{array}{l}\text { helps to socialize students int } \\
\text { in the larger society. }\end{array}$ & nguistically appropriate bilingual practices \\
\hline
\end{tabular}


Table 2: Some Suggestions on How to Use L1 in the L2 Classroom (Summarized from Lin, 1996, 2000; exemplifying classroom excerpts are omitted)

1. A teacher can strategically use L1 when she/he wants to appeal to a shared cultural value, or to address students as a member of the same cultural community, and to invoke some L1 cultural norm or value.

2. A teacher can intentionally use L1 to highlight to students that what she/he is saying is of such grave or urgent importance (e.g., for disciplining) that the usual rule to use L2 has been suspended.

3. A teacher can deliberately use L1 if she/he wishes to arouse student interest, establish a warmer and friendlier atmosphere, or build rapport with her/his students.

4. Teachers can give a quick L1 translation for L2 vocabulary or terms. Providing an L1 translation can promote bilingual academic knowledge and help students understand the subjects in both L1 and L2. Giving the Chinese meaning can also help students form richer multiple conceptual connections as the Chinese counterparts of English terms are often made up of common Chinese words that can sometimes enable students to infer, recognize and understand the meaning of the term better.

5. Teachers can deliberately use L1 to provide annotations or examples that help relate an unfamiliar L2 academic topic to the students' familiar L1 daily lives. This can help make school less alienating and more meaningful and relevant.

6. Teachers can purposefully use L1 to encourage class participation and discussion and to help elicit the knowledge and experiences that students bring into the classroom and help them transform that contribution into L2. For example, students can be permitted to discuss or work on a group task in Chinese initially and with the teacher's help produce an English version at the end.

7. If a student asks a question in L1, the teacher can help her/him rephrase it in L2. 
Table 3: Functional Distribution of Cantonese and English in the Teacher Talk of EMI Junior Secondary School Lessons in Hong Kong (Summarized from Johnson, 1983, 1985)

Johnson found a functional distribution of L1 and L2 across the following continua:

ENGLISH (L2) CANTONESE (L1)

TEXT-DEPENDENT .......................TEXT-INDEPENDENT

FORMAL.....................................INFORMAL

DIDACTIC .................................EXPLANATORY

MEMORY-BASED............................UNDERSTANDING-BASED 